\title{
LAS ESTRATEGIAS DEL CONTROL SOCIAL EN EL CAPITALISMO *
}

\author{
Dario Melossi \\ (Universidad de Bolonia, Italia)
}

En este trabajo se examinan las relaciones que existen entre un sistema económico capitalista y las formas de control social a las que el primero da lugar. A tal fin el autor se sitúa en una perspectiva crítica y utiliza los postulados de la teoría marxista de la sociedad. También utiliza el ponente las recientes concepciones que sobre el Poder, como forma de disciplinar a todas las fuerzas sociales, ha generado la crítica formulada al sistema de telaciones sociales propias del capitalismo.

Hipótesis tales como la relación existente entre el mercado de trabajo y la ejecución de las penas privativas de libertad, constituyen los ejemplos más diáfanos de las sugestivas aportaciones que se contienen en esta colaboracion.

* La traducción al castellano fue revisada por Angeł de Sola y Carles Viladás. 
Podemos considerar que la discusión sobre el nexo esencial entre acu. mulación de la plusvalía y dominio capitalista de la fuerza de trabajo en el lugar de producción constituye ya un dato definitivo del que hemos de partir. En efecto, no hay excedente de trabajo ni, por tanto, acumulación, si no hay management, si no hay organización capitalista del trabajo. Se trata de uno de los conceptos fundamentales sobre los que está construido el libro primero de El Capital (Marx, K., 1970), en relación a una orga. nización capitalista históricamente determinada que es la que podríamos definir como capitalismo competitivo (o «clásico», o «liberal», o «burgués», o como quiera llamárselo). Ya se ha observado también que en esa dimensión histórica Marx tiende a contraponer el despotismo capitalista en el lugat de producción a la anarquía del mercado, es decir, de la «esfera de circulación». En un artículo que escribí no hace muchos años, insistí excesivamente en esta suerte de contraposición entre ambas «esferas» (Melossi, D., 1976), como lo ha observado recientemente J. Lea (1979). Naturalmente, y según el modelo marxista «clásico», algo como una libre «esfera de circulación» no existe, o al menos no existe para el trabajador, para el proletario, para quien la única posible «circulación de bienes» es la de su propia fuerza de trabajo y para quien el único contrato imaginable es aquella suerte única de contrato - pero jcuán críticamente fundamental!cuya doble naturaleza tan magníficamente describen las primeras páginas de la obra de Marx y que --siempre en ese esquema teórico- tiene su esencia fuera de la esfeta juŕdica, a saber, en la esfera de producción. Para los «otros», para los propietarios, para quienes el serlo les permite acceder a todas las otras formas contractuales libres, la forma jurídica contractual es realmente el «paraíso de los derechos del hombre» (Marx, K., 1970, I, 1, 193).

Por otro lado, cuando cita otro pasaje de la obra de Marx - Jariado está atado... por hilos invisibles» $(1970$, I, 3, 17) - Lea parece sugerir que el trabajador asalariado está de algún modo "obligado a firmar" el contrato, lo cual no puede considerarse como válido así, simplemente, ni siquiera en los orígenes del modo de producción capitalista. Braverman observa: 
«El verbo to manage, del latín manus, esto es, mano, significaba originariamente adiestrar un caballo para que realizara los ejercicios del manège» (Braverman, H., 1978, 68).

Naturalmente, para adiestrar (manage) un caballo, primero hay que capturarlo y domesticarlo, y el éxito de este proceso depende en gran parte de las condiciones generales en que tiene lugar, resultando muy distinto, por ejemplo, en una granja aislada en medio de fértiles praderas que prometen hierba tierna y libertad más allá de una simple temporada, que en una metrópoli industrial con escasas posibilidades de supervivencia para los hombres - si no están integrados en una serie de relaciones socio. jurídicas-y mucho menos aún para los caballos. En todo caso, el proceso de domesticación y adiestramiento es largo y penoso. Seguramente no Jo fue menos para los hombres y las mujeres a los que les tocó vivir los orígenes del capitalismo y que se vieron reducidos a los espacios cerrados, la regularidad, el ambiente malsano, la monotonía y la disciplina de aquella situación. Leamos otra vez a Braverman:

«En el ámbito de las singulares e inéditas relaciones capita. listas, que presuponían un "libre contrato de trabajo", dichas relaciones debían obligat a quienes dependían de ellas al comporta. miento cotidiano que mejor podía servir sus intereses e imponer a los obreros la propia voluntad en el momento mismo en que llevaban a cabo un proceso de trabajo sobre una base contractual voluntaria. Este tipo de empresa poseía desde el primer momento una característica que según Clausewitz es típica de la guetra, es decir, la de ser movimiento en un medio resistente, en la medida en que implica el dominio de masas recalcitrantes» (Braverman, H., 1978, 68).

Sobre todo en los orígenes del modo de producción, esta resistencia se ponía de manifiesto en el intento de huir de la fábrica para sobrevivir por ottos medios, lo que parecía tanto más posible cuanto que - lo mismo que a nuestro caballo encerrado en la granja- el ambiente circundante y los campos, aún escasamente atacados por las relaciones de producción capitalisias, se mostraban propicios para ello. En efecto, uno de los objetivos del desarrollo capitalista habría de ser la destrucción de las viejas relaciones en el campo, también para inclinar la balanza a favor de su territotio, la ciudad, y quedar así con las manos libres frente a los antiguos campesinos convertidos en vagabundos, frente a aquellos "ociosos» cuya supervivencia dependía cada vez más del trabajo asalariado. Y sin embargo, con tal de huir de la fábrica, todavía quedaba abierta la puerta a la mendi- 
cidad, al latrocinio, al bandolerismo y a los oficios de la mala vida (Melossi, D., Pavarini, M., 1977, 84 ss.).

Nos encontramos aquí con estrategias diferentes, estrategias de poder y de resistencia que se valen de instrumentos distintos. Es muy difícil distinguir, por ejemplo, las fuerzas que actuaban en el mercado de trabajo de las que actuaban en la producción. Baste recordar que el paso de la inversión extensiva de capital a Ia profundización del capital en relación con los cambios en el mercado de trabajo es ya uno de los lugates comunes de la teoría marxista (Dobb, M., 1972, pp. 322 ss.).

Históricamente, y con mayor razón en el período "clásico» del capitalismo al que me estoy refiriendo, la fuerza de la clase obrera en el mercado de trabajo también era fuerza en la fábrica, proceso que, desde el punto de vista capitalista, ha producido por regla general un crecimiento en la composición orgánica del capital y lo que Dobb llama la «profundización» de la explotación. Tanto es así que la misma cuestión podría enunciarse diciendo que las relaciones en el metcado de trabajo --desde el punto de vista de las relaciones de poder entre las clases - ya estaban presentes, implícitas, en las relaciones de poder en la fábrica, y que, en verdad, podemos apreciarla en el grado y en el carácter de la resistencia obrera a la disciplina de fábrica, al management capitalista.

Como se cuenta en el libro de Karl Polanyi, La grande trastormazione (1974), antes del siglo pasado jamás había ocurrido que una sociedad aspirase a ser regida por una fuerza puramente económica. Esto es algo que sólo llegó con el capitalismo decimonónico, que colocó en el corazón de su funcionamiento ideal el metcado, es decir, un mecanismo autorregulado del cual la sociedad entera sería tan sólo un apéndice. Según este modelo, que por lo demás fue tenazmente perseguido como objetivo en la práctica, la fuerza de trabajo constituía una mercancía entre las otras mercancías. En consecuencia, como tal había que considerarla, aun cuando poseyera la característica — que, en última instancia, resultaría desagradable y molesta- de que no se podía tratarla «sin influir también en el individuo humano que es el portador de esta metcancía particular» (Polanyi, K., p. 94).

Todo este proceso implicó una transformación radical en la forma general de la autoridad, que dejó de ser visible para convertirse en invisible, un proceso en que la política debía ceder su lugat a la economía. O mejor aún: «Un mercado autorregulado sólo requiere la separación institucional de la sociedad en una esfera económica y otra política» (Polanyi, K., p. 92).

El carácter manifiesto de la autoridad bajo el poder medieval y luego absolutista cedió su lugar a un orden nuevo en el que el Estado habría desaparecido. $\mathrm{O}$ por lo menos éstas eran las intenciones.

Ciertamente, sólo se trataba de una tendencia, pero aquella «mano 
invisible» que regía el mercado, aquella nueva autoridad suprema destinada a sustituir la compleja maquinaria del Estado absolutista, debía extenderse por doquier y reproducirse si se pretendía que funcionase en serio, ante todo en el mercado. Aquella «mano invisible» debía regir la mente de los hombres y de las mujeres, al igual que toda la topografía de sus vidas. La entera estructura de la autoridad se vuelve invisible, al menos de la misma manera en que la teoría política del liberalismo hizo dimanat dicha estructura de un «bien común», de una "voluntad general», de una Grundnorm invisible del poder visibie. Del mismo modo, el principio de autoridad adoptó en la fábrica el aspecto de necesidad técnica, esa misma necesidad -destinada a perseguir el bien de quien organiza - que viene finalmente a presidir las otras organizaciones sociales. Basta pensar en la familia y en todo el proceso educativo.

En consecuencia, una autoridad invisible que emana «automáticamente» del correcto funcionamiento de un organismo social autorregulado. Un organismo de esta índole no necesita de autoridad manifiesta alguna. Concibe la política mucho más como mera técnica de gobierno que como conflicto de intereses y en ningún caso como choque de intereses - u «opciones ideales»- organizados. El mejor funcionamiento de la totalidad quedará garantizado por la suma de las motivaciones egóstas de cada individuo. No me interesa ahora la cuestión de si la utopía funciona o no. Me interesan mucho más, en cambio, algunos aspectos accesorios de este «mecanismo autorreguladon. Como se ha visto, entre sus supuestos básicos figuran -particularmente, como lo muestra Polanyi con toda clatidad- el que cada uno se orienta a la persecución de lo útil, que todo es mercancía y que toda mercancía está en el mercado (Polanyi, K., 1974, 88 ss.).

Entre todas elias encontramos algunas mercancías extrañas: el dinero, el trabajo y la tierra. «Sin embargo, el trabajo y la tierra no son otra cosa que los propios seres humanos que constituyen toda sociedad y el medio natural en que ésta existe. Incluirlos en el mecanismo del mercado significa subordinar a las leyes del mercado la esencia de la misma sociedad» (Polanyi, K., p. 92).

Pero hay más. También significa un grandioso proceso de transformación encaminado a la producción de aquellas mercancías que no están «naturalmente» listas para ser tratadas como tales. No sólo significa la apropiación privada de la tierra y de toda otra riqueza, sino también la creación de la fuerza de trabajo, el duro, difícil, penoso proceso de transformación de los trabajadores en fuerza de trabajo.

Ésta era la estrategia de aquel capitalismo. La utopía de una sociedad libertaria, de una sociedad sin poder, sin Estado, aparece finalmente como uno de los procesos más violentos y más autoritarios de la historia. El 
liberalismo está empeñado en conquistar su propia verdad. Es menester tedefnir la tealidad, rediseñarla de acuerdo con los principios del utilitarismo. Ha nacido una autoridad oculta, una Mano Invisible que trabaja, bajo la máscara del capital, para producir la propia sociedad y, al mismo tiempo, autorreproducirse. O de otro modo, el tecién nacido capital trabaja, bajo el disfraz de una Mano Invisible, en la producción de la propia sociedad y en su autorreproducción.

Este poder invisible/nueva autoridad/capital, debe crear, pues, su propio labour:

«Panopticon o la casa de inspección: que contiene la idea de un nuevo principio de construcción aplicable a cualquier tipo de establecimiento en el que sea necesario mantener bajo control personas, cualquiera que sea su naturaleza; y en particular penitenciarías, prisiones, industrias, casas de trabajo, casas para pobres, manufacturas, manicomios, lazaretos, hospitales y escuelas..., el mismo será aplicable..., sin excepciones, a cualquier establecimiento en que... se aspire a mantener a muchas personas bajo control. No importa que la finalidad sea muy diferente y hasta opuesta; ya se trate de castigar a los incorregibles, vigilar a los locos, corregir a los viciosos, aislar a los sospecbosos, bacer trabajar a los bolgazanes, socorrer a los desvalidos, cuidar de los enfermos, instruir en cualquier ramo de la actividad a quienes lo deseen, o bien conducir a la nueva generación por el camino de la educación.... (Bentham, J., 1962, presentación, 40).

Panopticon es la máquina mágica inventada para producir la nueva realidad del trabajo como mercancía, jtrabajo como fuerza de trabajo! Tiene razón Foucault cuando, al comentar la invención de Bentham, nos muestra la importancia de la separación entre ver y ser visto (Foucault, M., 1976, 220; Lea, J., 1979).

Todos somos libres. No hay dios ni señor alguno a quien rendir homenaje. Sólo existe esta máquina perfecta, dispuesta para el bien común, que es la acumulación del bien, de la riqueza (wealtb). Dentro de la máquina -que es la única posición posible- esta torre muda es el poder, invisible. O mejor aún, es la estructura, la Bau sobre la cual se apoya el management de cada uno sobre sí mismo. Es un a priori, un postulado. Se trata del tipo de poder, agrega aún Foucault $(1976,219)$, que sustentan aquellos que son su objeto.

El autor del Panopticon será también el autor de los Principles of Morals and Legislation, coincidencia que sólo puede asombrar a Aldous 
Huxley (1949). Si, según lo señalara Beccaria, el fin del Derecho penal, lo mismo que el de las otras ciencias de gobierno (Pasquino, P., 1978; Procacci, G., 1978), debía ser el de la máxima felicidad repartida entre la mayor cantidad posible de gente, Bentham no dudaba de ello un instante:

«... llamadles soldados, llamadies monjes, llamadles máquinas: lo mismo me da, con tal de que sean felices. Que sobre las guerras y las tempestades bueno es leer, pero la paz y la calma son mejores de disfrutar» (Bentham, J., 1962, 63, 64).

Se trata de la paz y la caima de la felicidad utilitaristas, de la paz y la calma de ese equilibrio en el que las necesidades y la producción se dan la mano y en el que la aparente anarquía del mercado se resuelve en el mejor de los mundos posibles. Es un orden que se persigue y se produce con máquinas e inventos, de los cuales el Panopticon tal vez sea uno de los más geniales ejemplos. Porque, en efecto, una vez más, este orden se basa sobre aquellos presupuestos que, desgraciadamente, no se encuentran en la naturaleza, sino gize han de ser manufacturados y, entre ellos, la fuerza de trabajo.

La violencia del Panopticon — que recojo aquí como representación de la multiforme ingeniería social de la época- está perfectamente integrada en el programa general del liberalismo, en la necesidad de estructurar la vida según parámetros definidos de tiempo y de espacio. Sobre estos sólidos fundamentos se apoyan las grandes categorías kantianas; es esta sólida torre central del poder lo que las garantiza. La institución total, y en particular la cárcel por su naturaleza ejemplar (Bentham, J., $1962,40)$, fue uno de los laboratorios privilegiados de esta producción de tiempo burgués, tal como lo señalan algunos autores (Foucault, M., 1976, 170 ss.; Melossi, D., Pavarini, M., 1977, 85 ss.; Ignatieff, M., 1978). En una reciente intervención sobre Capitalism and rule of law, Michael Ignatieff trataba de encontrar la relación entre esta primitiva política socialcarcelaria y la economía política clásica y en particular con el pensamiento de Adam Smith. La investigación se llevó a cabo en el mismo contexto en que el estudioso de Bentham, J. Annete (1979), desarrolló la suya, y Pasukanis (1975) tuvo la feliz intuición de distinguir el vínculo específico que une la forma carcelaria y la forma jurídico-penal utilizando precisamente el concepto burgués de tiempo (Kinsey, R., 1978; Melossi, D., 1978, 14). $Y$ es probable que haya sido $G$. Himmelfarb quien con mayor fuerza haya destacado el nexo profundo de Bentham, y del Bentham "panóptico», con la naciente tradición del pensamiento liberal abriendo de esta suerte el camino a los análisis más tecientes (1968). El Panopticon debe leerse en la línea Bentham - James Mill - John Stuart Mill. Como lo recuerda Himmel- 
farb, el plano panóptico no sólo sobrevive a la conversión de Bentham al radicalismo liberal, sino también fue aceptado de buen grado por los partidarios de aquelias posiciones, especialmente por el padre de J. S. Mill, James, quien acerca del Panopticon benthamita escribió en la Enciclopaedia Britannica que estaba tan bien presentado y probado, que todo aquel que quisiera seguir este camino, llevando ante sí bien alto el principio de utilidad, no podría hacer otra cosa que ir tras las huellas de Bentham (Mill, J., 1824, VI, 385).

Nada de esto significa que alguna vez se haya considerado el Panopticon como algo más que una idea ingeniosa, aunque algo extraña. Pese a los intensos y dilatados esfuetzos de Bentham para llegar a convertirse en director-empresario, con poderes absolutos, de su propio Panopticon, con el objeto de mancomunar la utilidad individual y la utilidad común (Himmelfarb, G., 1968, 42 ss.), semejante construcción nunca llegó a realizarse, salvo rarísimos casos (Evans, R., 1970; Markus, T., 1954). Natutalmente, esto no es muy importante en una perspectiva de genealogía del poder y no en el de una historia de la cárcel. $Y$, sin embargo, a mi juicio la intensa carga simbólica de la idea benthamita no es ajena al hecho de que raramente se la pusiera en práctica, si es que alguna vez se hizo. EI "principio de inspección», que es la idea que servía de base al Panopticon («verlo todo sin ser visto por nadie») representa uno de los modelos más puros de la primitiva disciplina manufacturera (la idea originatia del arquitecto Samuel, hermano de Bentham, trataba de responder al problema del control de las cuadrillas de un astillero construido en las propiedades del príncipe Potemkin en Rusia). Pero no es una manufactura. Es su representación. Es el principio de inspección manufacturero socializado y reproducido cuando la manufactura ya está terminada. De un modo brutal, el Panopticon es ya "pieza de museo» en el momento mismo de ser ideado, pieza del museo de la industria. Esto se comprende fácilmente si se tiene en cuenta su abstracción utópica, el ser representación de «panoptismo». EI mismo respondía a las necesidades de un Bentham flósofo utilitarista en tanto reproducía el modelo de dominación capitalista que debía socializarse a través de la teoría, único modelo de que se disponfa en aquel momento. Pero si el Bentham flósofo hubiera conseguido liegat a ser también el Bentham director de cárcel-contratista de mano de obra (jailer-contractor), tal como se lo había propuesto pero nunca conseguido, la escasa practicabilidad del instrumento panóptico se habría manifestado con absoluta claridad. Es cierto que aún quedaba la especificidad de la forma cárcel, su carácter de representación extrema del lifestyle burgués, de disciplina «moral». Pero una vez desaparecida la disciplina manufacturera específica basada en el «ojo del patrón» o de su capataz, otra será la fórmula arqui- 
tectónica que se adopte. A que así sea concurre también un motivo que se repite a lo largo de la historia de la institución carcelaria. Se trata de que la decisión de invertir capitales en esta institución y por tanto de construir nuevos establecimientos aparece siempre en concomitancia con políticas carcelarias productivas (Rusche, G., Kirchheimer, O., 1978) según la perspectiva de que el trabajo forzado compensa los gastos. De lo contrario, cualquier lugar -antiguos lazaretos, antiguos conventos, antiguos cuarteles, etc.- podría usarse para hospedat a los detenidos a pesar de que ello llevara al más terrible hacinamiento. En efecto, cuando la política penal no es productivista, es tendencialmente «malthusiana»-de acuerdo con la conocida tesis de Georg Rusche- y tiene muy poco en cuenta el lugar donde se ha de depositar a los detenidos. Si pensamos, por ejemplo, en la casa de trabajo de Amsterdam, de finales del siglo xvi, que sirvió como modelo a muchas otras en toda Europa, advertimos que en realidad e inmediatamente constituía una manufactura (Sellin, T., 1944). No se trataba de una representación de ningún tipo; lo era efectivamente. Era la disciplina de la fuerza de trabajo según un modelo histórico cual es el de la manufactura. Pero el caso del Panopticon es, por cierto, muy diferente. Dos siglos después de Amsterdam, y a pocos años de la revolución francesa, el poder burgués estaba en condiciones de producir símbolos, tipos ideales, materializaciones de la ideología. Aun cuando, como seguramente lo hizo Bentham, tomemos en cuenta la exigüidad de capital necesario para una institución en la que los trabajadores estaban obligados a aceptar las condiciones de un «capitalista que se encuentra en posición de monopolio» (Bentham, J., 1962, 54), la particular estructura tecnológica del Panopticon incorpora la de la manufactura, en la que la disciplina queda asegurada ante todo por la presencia de un vigilante, del «superintendente» (Lea, J., 1979). En la utopía benthamita no hay máquinas, lo que, a finales del siglo xvini, hacía de una utopía de este tipo algo ya bastante obsoleto, a tal punto que en el posterior Postcript Bentham modificó el propio proyecto inicial llevando el número preciso de detenidos de uno a cuatro por celda, con la intención de enfrentar de un modo más realista el problema de la organización del trabajo (Himmerfarb, G., 1968, 45; Melossi, D., Pavarini, M., 1979, 69). El Panopticon es la forma, el design de una disciplina, experimentada en el período de los orígenes de la fábrica y heredada como motivo conducto: de «todo establecimiento» en el que «haya que tener bajo control personas de toda clase», es decir, el principio de inspección.

De la fábrica a la sociedad -es decit, a esa serie de instituciones creadas poco antes, llamadas casas de trabajo, hospicios para pobres, hos. pitales, reformatorios, escuelas, etcétera. De estas instituciones, nuevamente a la sociedad. Como observa Braverman: 
«En consecuencia, para el capitalista es esencial que el control del proceso de trabajo pase de las manos del obrero a las suyas. Este paso se presenta en la historia como la alienación progresiva del proceso de producción del obrero; para el capitalista, esto mismo se presenta como el problema de la dirección (management)" (Braverman, H., 1978, 58).

Por lo tanto, al trabajador no sólo se le expropian los medios de producción, sino que poco a poco se le expropia también el propio oficio, no sólo la propiedad de los instrumentos de trabajo, sino también el control de éstos. Este control del proceso de trabajo pasa de la cabeza del obrero al general intellect del capital. Gradual y sistemáticamente, la fuerza de trabajo del obrero es separada del control mental del obrero sobre ella. Por tanto, con el avance del proceso de mercantilización avanza también un proceso de transformación de la mercancía fuerza de trabajo, la cual se vuelve cada vez más semejante a un suministro de energía en formas determinadas. Obviamente, la conciencia del proceso de trabajo se mantiene, pero arrancada del obrero y centralizada en el capital. Sin embargo, a fin de que el obrero siga siendo fuerza de trabajo (o se convierta en fuerza de trabajo), es menester que él/ella esté siempre bajo la guía de aquella conciencia, la que ha de asumirse automáticamente antes, dutante y después del proceso de trabajo. A este respecto, la utopía capitalista no consiste tanto en la división obrera entre una «cabeza libre» y unas «manos que no saben lo que hacen» -acaso sea éste el camino que tomará o tratará de tomar, la resistencia obrera-, sino en el hecho de poseer directamente, a través del mando mismo, Ia energía física, o, mejor aún, la disponibilidad laboral de un obrero «sin cabeza», unidad descentrada y fisiológicamente autónoma con autorregulación capitalista. O mejor, obrero "con cabeza», pero con cabeza producida y abastecida por el capital.

Naturalmente, la distinción entre «cabeza» y «energía física» se debe únicamente a razones de comodidad, pero, en este contexto, "cabeza» no significa otra cosa que mando, un mando que atraviesa el cuerpo entero de la fuerza de trabajo. Es precisamente este proceso productivo del cuerpo heterónomo de la fuerza de trabajo (o mejor, las estrategias que tienden a producir este cuerpo...) el tema en el que quiero detenerme. No sólo se trata del problema de la reproducción natural del proletariado:

«No es suficiente que las condiciones de trabajo se presentem como capital por un lado y que, por otro, se presenten hombres que no tienen otra cosa que vender que su propia fuerza de trabajo. $\mathrm{Y}$ tampoco es suficiente obligar a estos hombres a venderse voluntariamente. A medida que la producción capitalista avanza, se 
desarrolla una clase obrera que, por educación, tradición y hábitos, reconoce como leyes naturales obvias las exigencias de este modo de producción. La organización del proceso de producción capitalista desarrollado quiebra toda resistencia; la permanente producción de una supetpoblación relativa mantiene la ley de oferta y demanda de trabajo, y por tanto el salario laboral, dentro de límites que corresponden a las necesidades de valorización del capital; la silenciosa coacción de las relaciones económicas imprime su sello al dominio del capitalista sobre el obrero» (Marx, K., 1970, I, 3, 196).

¿Cómo se producen esta «educación, tradiciones y hábitos» en una estructura en cuyo interior el proceso de trabajo se presenta al obrero como dominio capitalista, disciplina y organización a la que ha de adherirse y en la que ha de adiestrarse? En otros términos, ¿qué curso siguen las estrategias constructoras del cuerpo de la fuerza de trabajo, por dónde pasan? O de otra manera aún: ccómo producir esta metcancía extraña que es la fuerza de trabajo? Estos son los interrogantes a los que Bentham intenta responder. Se trata de las instituciones sociales creadas en la edad moderna, profusamente mencionadas en las primeras páginas del Panopticon bajo eł dominio común del principio de inspección, garante de la disciplina, las que constituirán la fábrica productora de esta mercancía especial que, única entre todas, aumenta la tiqueza de quien la usa.

Buscar el origen y los desarrollos de estas diversas instituciones equivaldría a la «presuntuosa» aspiración de trazar una genealogía de la moral (Foucault, M., 1977, 135) y a seguir las huellas de Foucault, especialmente en Sorvegliare e punire. Los orígenes de los sentimientos morales, del sentido de la culpa, del «demasiado humano»: las mnemotécnicas de Nietzsche - la originaria violencia de la pena en la constitución moral del hombre civil (Nietzsche, F., 1977, 74 ss.) - constituyen el punto de partida implícito del texto de Foucault, de su investigación de las disciplinas punitivas (Foucault, M., 1977, 29 ss.; Rajchman, J., 1978). Efectivamente, Sorvegliare e punire está dedicado precisamente a esto, es decir, a la identificación de las estrategias institucionales a través de las cuales se construyó el cuerpo de la fuerza de trabajo, el cuerpo de los dominados. Las técnicas disciplinarias de la cárcel, de la escuela o de la manufactura actúan en el sentido de un específico objetivo bumano, de una estrategia compleja de reproducción y ampliación de las relaciones sociales capitalistas, del establecimiento de la firme hegemonía de estas últimas. Sin ideología, sin estructuras ni superestructuras. Simplemente ejercitando el propio poder, construyendo la propia realidad. 
Se trata, pues, del hombre como unidad descentrada de dominio sobre el individuo. O bien, para usar otros lenguajes, la transformación de la religiosidad medieval externa en la religiosidad interna de la reforma, el «sacerdote interno» de Marx $(1950,405)$ o el superyó de Freud. La gran investigación de la escuela de Frankfurt acerca de autoridad y familia (Horkbeimer, M., y otros, 1974) llamó la atención sobre la constitución de la estructura familiar moderna, patriarcal y monocelular en el período de la génesis capitalista. El padre, pues, como modelo de hombre. Las figuras del señor y del siervo se reproducen en el individuo a través de la institución famitiar, primer eslabón de la cadena institucional que reproduce/ trabaja para reproducir las relaciones sociales en su conjunto. La escisión entre poder/saber y poder/fuerza, «lucha de clases», es inherente a todo individuo. La mano invisible, el guardián invisible de la torte central, constituye ante todo el dominio interno de hombres y mujeres. La preocupación por garantizar esta socialización de conjunto constituía el fundamento de la afirmación de Owen de que los trabajadores son máquinas, ciertamente, pero máquinas vivas, que no se trata simplemente de consumir, sino también de reproducir. Si bien no es posible volver a crear un Panopticon completo (salvo en el caso de las instituciones «totales») dado que el tiempo de trabajo no se extiende a la totalidad del tiempo, es posible, con todo, crear este continutum institucional, esta New Lanark en la que se realice el sıeño filantrópico y pedagógico del capital, su utopía de una completa reducción obrera a fuerza de trabajo. Un continum bajo estricto control. El panoptismo no necesita un Panopticon perpetuo como cree John Lea (1979). Es suficiente con la hegemonía capitalista sobre las instituciones, ya se trate de instituciones de trabajo, ya se trate de las de la fe, del afecto, de la diversión, etc.

Pero precisamente esta hegemonía no es nunca segura. No es casual que Foucault describa estrategias que se convierten en fracasos para volver a presentarse tepentinamente como estrategias nuevas y distintas, tal como ocurre en el caso de la cárcel (Foucault, M., 1976, 282 ss.). Braverman, por su parte, nos recuerda a Von Clausewitz, para quien el management es movimiento en un medio resistente (Braverman, $\mathrm{H} ., 1978,68$ ).

A las estrategias de control, a las técnicas de vigilancia y a la microfísica del poder por parte del capital, responden una resistencia y una cultura obrera que transforman aquellas técnicas, aquelia estrategia, aquel poder en el momento en que son el resultado de la resistencia misma a ellas opuesta. Si bien no hay existencia pura y originaria que, como en el sueño romántico, escape a la producción de quien sabe ejercer su propio poder, este poder tampoco se produce en el laboratotio. El Panopticon bien puede ser una especie de laboratorio del poder, pero no es casual 
que un laboratorio como éste no haya sido nunca o casi nunca implantado. La investigación histótica nos ha proporcionado incontables ejemplos de las resistencias de distinta índole contra el Panopticon. Más específicamente, nos ha mostrado cómo las estrategias, las tecnologías de control, la vigilancia, etc., hunden su raíz propia en la lucha de clases, al menos en la medida en que las tecnologías de resistencia están determinadas por las de control y vigilancia. Ya he recordado todo esto en otro lugar (Melossi, D., 1979). En consecuencia, la afirmación de que Foucault habría «inventado» esa «nueva concepción del poder que se buscaba sin saber encontrarla ni enunciarla» (Deleuze, G., 1976, 30, 31) y de que esta contcepción sería «alternativa» a la marxista porque esta última reduce la cuestión del poder a la del control del aparato estatal (Deleuze, G., ibidem; Pasquino, P., 1978; Donzelot, J., 1978), me parece una afirmación por to menos tan dudosa cono la que viene inmediatamente después, y que sostiene que «toda economía, por ejemplo la tienda o la fábrica, presupone estos mecanismos de poder" (Deleuze, G., 1976, 33). De este modo, casi parece que se trazaran nuevas y diferentes coordenadas de interpretación que hacen surgir «en toda sociedad» esta «nueva concepción del poder», que se presenta como alternativa a la concepción tradicional identificada con la teoría marxista. A mi juicio, se trata de la enésima reedición del modo de pensar que intenta salii al paso de cierto economicismo o reduccionismo maxxista, pero no con un discurso nuevo, sino simplemente añadiendo al matxismo «algo distinto», «una concepción mueva», en la que, por otra parte, difícilmente se logra disimular su tufo «espiritual». Por el contrario, estos mecanismos de poder no sólo cambian enormemente al mismo tiempo que lo hacen las diversas economías, sino que la relación entre «microfísica del poder» de Foucault y «macrofísica» marxista no es la de instancias «aiternativas», sino que se plantea como relación entre discursos acerca del poder bajo diferentes condiciones. Más específicamente: la tradición marxista, lo mismo que un «movimiento obrero», surge de las profundidades de la cotidianidad en que se asienta el discurso de Foucault acerca del poder $\mathrm{y}$, sobre todo, de la fábrica (ipero no sólo de ésta!). Se trata del problema de los recursos a que se apela para abordar precisamente esta cuestión de poner a la orden del día un instrumento particular —el partido- para un objetivo particular -la toma del poder del Estado (ya sea a través de formas socialdemócratas o de formas leninistas). Este desplazamiento de campos, del micto al macro, ha robustecido el movimiento. El que hoy se tenga la impresión de que se marcha hacia el agotamiento de las condiciones que convertían al binomio partido-Estado en el eje de la política obrera, es lo que explica que los intelectuales inventen «concepciones nuevas». 
Sin embargo y entretanto, la ortodoxia toarxista se identificó con la cuestión del maxxismo y del Estado precisan:ente en el período durante el cual la Autoridad Invisible del suef̃o liberul y librecambista se rompió en mil pedazos y se precipitó en una crisis qute, entre la década de 1870 y la de 1930, arrastró consigo a toda la «civili sación europea»:

«La civilización del siglo XIx... se disgregó como resultado... [de las]... medidas adoptadas por la sociedad para no verse anulada a su vez por la acción del mercado autorregulador» (Polanyi, K., 1974, 311).

La sociedad se ve obligada a «tomar redidas», a autorregularse, a racionalizar. Lo político se libera de la esclavitud de lo económico: put politics in command! Es necesario abotdar, assalizar, definir, adueñarse de esa informe y opaca constelación de fenómeno: que se creía gobernada por un poder que ya era mítico: es necesario intervenir para impedir las consecuencias fatales del funcionamiento automático de aquélla.

Ya se trate de poner en orden el desastıoso panorama económico de las décadas de los veinte y los treinta, ya se rate de afrontar la profunda crisis de la conciencia del hombre europeo y de su psiquis, es menester entrar en el desorden, en la crisis, intervenir en ella para conocerla y transformarla y apuntar a un nuevo equilibr.o, no ya fruto del «destino magníftco y progresista» de un orden autorrę̧ulado, sino de una intervención provista de poder, consciente del objetiro a alcanzar y de la técnica necesaria para lograrlo. Sin esperanza: el orden encantado de otros tiempos no será restablecido, no hay nada a lo que volver, pues sólo es nuestro lo que se conquista. Pata Freud, que repress nta un gozne decisivo entre Ios dos mundos (Rella, F., 1978, 13 ss.), ni) se trata de desvelar ni de recrear ninguna inocencia perdida; el análisis transforma al propio objeto, es práctica interminable, no descubre, transiorma (Freud, S., 1977). El inconsciente es ptoducido e inmediatamente puesto en duda. El político to ataca tratando de hacerlo suyo, de dominarlo. En la invisibilidad del orden feliz ya destruido reaparece la autoridad, perc es una fuetza desnuda, desprovista de toda investidura real. Debe salir a la luz y conquistar la propia realidad. El poder no puede seguir funcionanilo de manera invisible. Debe mostrarse y justificarse. Debe ser democráticc, y legítimo.

Peto este mostrarse (y extenderse) en lo social significa que al mismo tiempo tiene que incorporarse y ocultarse en $\mathrm{l}_{\mathrm{i}}$ técnica. Después del enorme crecimiento del poder obrero en las dos pr.meras décadas de este siglo (Cacciari, M., 1972; Bologna, S., 1972) el ranagement al interior de la fábrica se regitá cada vez más por la ptopi: tecnología del proceso pro- 
ductivo. La microfísica del poder se vuelve científica con el scientific management:

«La máquina ofrece a la dirección [management, $\mathrm{n}$. de A.] la oportunidad de realizar, con instrumentos absolutamente mecánicos, lo que anteriormente había tratado de conseguir a través de medios organizativos y disciplinarios» (Braverman, H., 1978, 193).

La disciplina se transforma, se incorpora a las máquinas. El trabajador es expropiado de todo saber, ya incorporado en el cuerpo muerto del capital, con lo cual se le corta de taíz la fuerza, que en ese período aún se basaba en el control del propio oficio. Se trata de la respuesta capitalista a una clase obrera que había llegado a la Revolución de Octubre, al «socialismo realizado», precisamente a través del instrumento del partido, máquina para la conquista del poder (del «macropoder»). Y entonces se cortan las alas a la fuerza de clase mediante la instrumentación de procesos de revolución pasiva (Gramsci, A., 1975, II, 1227 ss., III, 2140); el socialismo se vuelve tarea del capital y de la alianza política de la que éste forma parte. Es así como la época del fordismo y del taylorismo es también la época de la legitimación. La clase obrera entrega conscientemente su propia fuerza de trabajo, tanto en cantidad como en calidad, sentada a la mesa de las negociaciones políticas. La autoridad abierta, intervencionista y autolegitimadora del Estado capitalista de la década de los treinta se ve obligada a establecer pactos con la clase obrera organizada. A esto se ha dado el nombre de políticas de consenso, de legitimación, de monetización.

Este Estado intervencionista y keynesiano del período comprendido entre la década de los treinta y la de los sesenta asume masivamente la tarea de las estrategias de control social. Se trata de una característica general de los «revolucionarios años treinta» (Polanyi, K., 1974, 26 ss.), que pasa por distintas experiencias: la del socialismo realizado, la del nazifascismo y la del New Deal. Esto quiere decir que, pese a las enormes diferencias, se comprueba una imputación tendencial de los aparatos de masa que se habían desarrollado en las décadas anteriores al Estado: la crítica al libetalismo, implícita en la constitución de una sociedad de masa, es asumida por el Estado, que lo transforma radicalmente. Se intenta resolver el problema de la oposición entre masa y Estado (liberal) organizando a las masas en el Estado (por supuesto que los modos en que se opera esta organización son extremadamente distintos en los tres modelos mencionados). Estos nuevos procesos tienden a generalizar, aunque también a debilitar, el antiguo carácter "panóptico» del control social; la necesidad de un poder visible bace perder la fe en (y ta eficacia de) un funcionamiento 
automático de la «máquina» productiva del bombre disciplinado y moral, según la indicación de Bentham. En cambio, el político saldrá triunfante en la búsqueda de consenso y de legitimación. Por un lado, la instauración de la escolaridad y del servicio militar de masas llevan a cabo el proceso de socialización de las relaciones de producción capitalistas que aseguta el carácter natural del mismo y la acogida espontánea y mecánica del automatismo fabtil. Pero, por otro lado, después de las agitaciones sociales del periodo comprendido entre las dos grandes depresiones, es preciso abandonar todo sueño de dominar la fuetza de rabajo de manera absoluta. Como recuerda John Lea citando a Gramsci, «el nuevo automatismo del proceso de trabajo libera mentalmente al tral ajador de la subordinación a la autoridad del capital» (Lea, J., 1979; Gramsci, A., 1975, III, 2170-71).

La aceptación de la relación social capitilista y de la apariencia de hecho natural de esta relación implica tambitn la capacidad obrera para aceptar las reglas de juego, tanto en la fábrica somo en el Estado, en tanto fuetza de trabajo y en tanto clase. La relaciór del trabajo consigo mismo en tanto fuerza de trabajo, pura fuente de desgaste de energía, no sólo permite el control del desgaste, sino también li división entre este aspecto y el aspecto políico, la capacidad para jugar distintas partidas al mismo tiempo. La organización obrera, a caballo ent:e ambos siglos, ba vencido toda veleidad capitalista de dominar directamente a la fuerza de trabajo, de adueñarse de la cabeza obrera. Por el contrario, se impone la contratación entre potencias autónomas.

De esta manera, en la estrategia capitalista del control social se va sedimentando una fase primaria, que en lo esencial coincide con la escuela de masas, administrada o hasta directamente controlada por el Estado, y que tiende cada vez más a cumplir también las funciones de la institución familiar (Freud, S., 1971; Horkheimer, M., 1549; Mitscherlich, A, 1969), y una fase secundatia, de tipo esencialmente voluntario y asociativo, en las que es mucho más fuerte el choque entre las estrategias de control y resistencia. En efecto, además del propio sindicato (Lea, J., 1979) y de los partidos políticos, se pueden recordar las mas vas campañas de «moralización» y de "americanización» de la gran industria norteamericana que culminarían en el prohibicionismo (Calvi, G.. 1979; Gramsci, A., 1975, III, 2164 ss.), lo mismo que el asociacionismo «de después del trabajo», de cuño fascista (De Grazia, V., 1978). Junto con estas reformas, en la década de los treinta se llevará a cabo el establecimiento de dos instituciones sociales que habian ido adquiriendo importancia $y$ vigor en las décadas anteriores: el sistema de la asistencia que vuelve it ser outdoor, bajo la forma de tédito o de servicio y no necesariamente ligado a la internación como se había pretendido en la época liberal (Piven, F.., Cloward, R., 1972), y 
una fuerza específica de policía, que dependía del poder público (C. R. C. J., 1975). Es evidente que estos procesos no son obra de algún «cerebro» o «plan» capitalista, sino que son la resultante de luchas, de formas organizativas distintas en las diferentes sociedades y entre una zona y otra, en las que la iniciativa de las diversas capas y estratos sociales es, en cada caso, la que predomina en un juego confuso de choques y alianzas, $\mathrm{La}$ iniciativa obrera es la que obliga a las diversas estrategias de control a desplazarse de la fábrica al territorio en una unidad inescindible de conquista obrera y «respuesta» capitalista, de control y autonomía, una unidad que caracterizará cada vez más la sociedad de masas del capitalismo de las grandes corporations, del corporate capitalism.

Esta suerte de nuevo "panoptismo contratado», al que recurren la lucha y el conflicto y al que caracteriza la visibilidad de un poder en busca de legitimación, ha sepultado al viejo panoptismo maquinista de Bentham $o$, tal vez mejor, lo somete a discusión, lo pone en crisis. En el fondo de esta crisis hay un problema central, que es el del carácter puramente automático de la disciplina de fábrica. Después de Taylor, la cárcel como proyecto antropológico, la cárcel decimonónica, pierde todo sentido. La cárcel, lo mismo que las otras instituciones de control, deja dramáticamente de lado la escisión que se ha venido creando en la figura obrera entre la «memoria muscular y nerviosa» del trabajo de la que habla Gramsci, y la «libertad» de la cabeza del obteto, de su política, lo que estructuralmente se muestra en la fábrica con la sustitución del poder del «superintendente» por el de la cadena de montaje. La forma-cárcel, construida sobre la base determinada y obsoleta de la forma-fábrica, se vuelve tremendamente inadecuada para desarrollar las funciones de disciplina y de control para las que había sido concebida. Así, durante todo el siglo xix y el $\mathrm{xx}$ se asiste a un proceso de diversificación y especificación de las diversas instituciones que Bentham, como se recordó, distinguía sólo nominalmente por la diversidad de los sujetos a los que se refería. Tal vez sea éste el problema que subyace en el fondo del fracaso de lo carcelario repentinamente identificado al final del trabajo de Foucault. Se trataría aquí de trazar la genealogía de las diversas instituciones y de las diversas disciplinas, para reconstruir los diversos recorridos que han seguido: no sólo fábricas y cárceles, sino también hospitales, hospitales psiquiátricos, escuelas, etc. Estas instituciones se extienden por el cuerpo social, se fragmentan, se diversifican, se extinguen y se funden en intervenciones que ya no son de índole institucional y que se fueron desarrollando al lado de los viejos aparatos. Cada una de las instituciones -repito- sigue un propio y diferente destino, que corresponde a las características diferentes a las que responde (piénsese, por ejemplo, en la extremada complejidad 
que ha ido asumiendo un aparato como el escolar). El petiodo de los años veinte y treinta adquieze particulat significación precisamente porque es una suerte de puente entre las antiguas y las yuevas estrategias de control. Tomemos una vez más el caso de la instítución carcelaria. A lo largo de todo el período comprendido entre las últiras décadas del siglo pasado y los años veinte de este siglo, ha tenido lugar un proceso que se ha def. nido como excarcelación (Scull, A., 1977), y que se ha dado en todos los principales países capitalistas de Occidente: Gran Bretaña, Francia, Alemania (Rusche, G., Kirchheimer, O., 1978, 233 ss.), Italia (Melossi, D., 1976b), Estados Unidos y los países escandinavos (Christie, N., 1968; Snare, A., 1977). Pero entre las dos guetras se desarrolla un doble orden de fenómenos. Por un lado, la institución carcelaria se revigoriza, y, por otro, comienzan a crearse una serie de instrumentos diferenciados que permiten una intervención de tipo no carcelario sobre el criminal, como la probation, la parole, las medidas especiale's para los menores, etc., instrumentos estrictamente ligados a la extensión de las redes asistenciales y policiales en la década de los veinte. Se traté de un reconocimiento de la crisis definitiva de la cárcel, respecto a su forma originaria. ¡En la sociedad de masas la disciplina cuenta con instrumentos muy distintos de aquella vieja herramienta! Por ello, parece estar en lo cierto quien habla de que la cárcel se vuelve productora de servicios para la sociedad capitalista, productora de delincuencia (Foucault, M., 1976, 282 ss.), instrumento de control interno al más generał, de mera custodia y disuasión (Cohen, S., 1975; Pavarini, M., 1978), de bifurcación del control criminal más que de excarcelación (Matthews, R., 1979). Por tanto, no es casual que uno de los poquísimos ejemplos de construcción de una cárcel panóptica sea el de Stateville, Illinois, en 1924, a corta distancia del corazón paipitante de las cadenas de montaje de Ford. Pero casi de inmediato se abandona la estructura panóptica, y el orden se mantiene a través de la más dura disciplina interna (Jacobs, J. B., 1977). Desp̣ués de los años treinta, du* rante cuyo transcurso se detiene en muchos países el proceso de «excarcelación», la evolución de la población carcelaria se vuelve menos unívoca. En efecto, de 1945 en adelante, las tendencias son opuestas según los países. Sin embargo, parece prevalecer una tendencia uniforme o cíclica de fondo (Blumstein, A., Cohen, J., 1973), qute, en Estados Unidos —único país, que yo sepa, objeto de semejante investigación-, es permanentemente paraleia a la de la amplitud del desempleo (Jankovic, I., 1977; Greenberg, D., 1977). Sobre esta base se podtría, pues, formular una hipótesis de trabajo según la cual en los años de maduración del capitalismo moderno - - de 1870 a 1930 aproximadamente-m la institución carcelaria habría perdido importancia, extensión y condición privilegiada para con- 
«Papers»: Revista de Sociologia

solidarse luego en una suerte de duro núcleo central del sistema de control, cuya amplitud fluctúa al compás de la amplitud de la marginalidad, y esta hipótesis, como ya he recordado en otro lugar (Melossi, D., 1978), armoniza también con la hipótesis general de Georg Rusche acerca de la relación entre pena y mercado de trabajo.

Los «fabulosos años sesenta» señalan al mismo tiempo la culminación del intervencionismo del Estado keynesiano y su colapso. Se abre así la crisis en la que estamos profundamente inmersos, a pesar de la apariencia del actual y provisional cierre a la derecha. En la segunda mitad de la década de los sesenta se produjo un hecho en gran parte nuevo, cual fue la aparición de una etapa de lucha obrera extremadamente amplia y generalizada en el corazón mismo del sistema capitalista, acompañada al mismo tiempo de luchas que sacudieron los fundamentos de instituciones sociales tales como escuelas, cárceles, hospitales psiquiátricos, cuarteles, y hasta la propia institución familiar. No es casual que la explosión de este movimiento "antiinstitucional» o «antiautoritario», como se le ha definido, haya tenido lugar simultáneamente a una fase particular de la lucha obrera, que por primera vez ponía en discusión el propio dominio del capital sobre la clase, la organización capitalista del trabajo. Entre las luchas obretas y las luchas antiinstitucionales no es que hubiera conexion genérica, sino que era la madurez de la Iucha obrera, sus contenidos, los que, al hegemonizar - aunque al comienzo sólo fuera de modo implícito- el movimiento genetal, asumía cada vez más el carácter de movimiento de conjunto contra el trabajo.

Naturalmente, también aquí se puede volver a comprobat la presencia de una determinada relación entre la actitud obreta respecto de la disciplina y el management y la estucturación del mercado de trabajo. Tarantelli, en un reciente librito, nos recuerda que

«la masiva incorporación al mercado de trabajo "en el 68 ", de los "dieciochoañeros" nacidos "en el 50" y que habían iniciado la escuela primaria coincidiendo con el school-boom postbélico de mediados de los años cincuenta, inmediatamente después de los primeros esfuerzos de reconstrucción posteriores a la guerra (con la anticipación de unos años por parte de Estados Unidos, que se veía libre de tales esfuerzos), sentaba las bases de un cambio de guardia generacional necesario a los fines de una comprensión correcta de la contemporaneidad del conflicto.

"Si , en mérito a la sencillez de la exposición, se nos permite una burda esquematización - -que sólo una (deseable) investigación empírica en el marco de cada país podría articular y cuali- 
Las estrategias del control social en el capitalismo

ficar adecuadamente-m, el "individuo-tipo", que constituye la bipótesis de este cambio de guardia generacional común a todos los países industrializados, nace en 1950 (como consecuencia del baby-boom postbélico), cursa el primer año de escuela primaria - a los seis de edad-m en 1955 (como consecuencia del scboolboom postbélico) y se diploma (inevitablemente) en 1967-1968, justo al amanecer del mayo francés, de! otoño caliente italiano, etc; es decir, al amanecer y como detonidor - que no causa, como en seguida veremos- "predeterminado" —nótese- desde el año 1950, de la contemporaneidad del corflicto a partir de la segunda mitad de los años sesenta. Estados Unidos y Canadá, precisamente por estar exentos de un esfuerzo de teconstrucción postbélica, anticipan en cuatro o cinco años todas estas fechas, $y$, en efecto, el social unrest se inicia ya a partir de los primeros años sesenta (si bien luego - lo mismo que en los o:ros países- se ampliaría a finales de la década, como consecuencia también de la guerra de Vietnam)» (Tarantelli, E., 1978, 35, 36).

Para esta generación no hubo depresión económica, escasez ni sufrimientos derivados de la guerra. Sus expectativas se vinculan a la prepa. ración intelectual, bien o mal realizada. La «tigidez» de esta fuerza de trabajo es muy grande. La misma trabajará bajo sus propias condiciones -prácticamente ausentes en la demanda de trabajo en el mercado- o bien, de hecho, no trabajatá. Es otra vez Tirrantelli quien nos recuerda cómo la crisis de los años sesenta no fue crisis del «modelo económico (keynesiano)», sino del más general «paradigma sociopolítico» (Tarante. 1li, E., 1978, 61). El colapso del mercado di: trabajo juvenil se produjo simultáneamente al colapso de las instituciones de disciplina $\mathrm{y}$, sobre todo, de la escuela y del servicio militar masivo, cue cada vez se usaban más para "ocultar» el desempleo, Para decirlo senc llamente, aparece en el mercado toda una nueva generación de trabajadores (potenciales) que no reconoce racionalidad ni legitimidad algunas a las formas dominantes de organización y de ética del trabajo, ni a la red institucional creada con el fin de garantizar tales formas. Esta nueva clase obrera expresa una demanda, tanto respecto del trabajo como del ambiente social más general, demanda que es profundamente subversiva para las condiciones dadas. $\mathrm{La}$ autoridad intervencionista y autolegitimante erigida en los años treinta se esfuerza cada vez más en responder a la demanda político-social que se le plantea. Lo que se ha transformado es el material sobre el cual la politica keynesiana estaba llamada a intervenir. i Abora lo importante es si el 
aumento de la demanda efectiva surge a través de la construcción de hospitales o de pirámides! (Tarantelli, E., 1978, 93).

También se ha definido este proceso como crisis de legitimación. O'Connor, por ejemplo, ha mostrado cómo las funciones estatales de garantizar al mismo tiempo la acumulación y la legitimación fueron cada vez más contradictorias entre sí y cómo se fueron constituyendo en mutuos obstáculos (1977). La persecución simultánea de ambas funciones se ha vuelto cada vez más difícil durante los años sesenta. Las diversas formas en las que se manifestara el rechazo del trabajo (en las condiciones dadas) en la fábrica - luchas sindicales, huelgas salvajes, absentismo, turnover, etc.golpearon duramente la capacidad del sistema para acumular, a la vez que aumentaban enormemente la presión sobre los gastos sociales, en especial sobre la asistencia y los servicios (Piven, F., Clowardm, R., 1972; Offe, C., 1977), justamente como resultado del aumento de la demanda obrera referida tanto al trabajo como a la calidad de vida. La crisis fiscal del Estado es el rostro con el que esta fase determinada de la lucha de clases se muestra a las administraciones públicas y a los ciudadanos de las metrópolis. En especial en Estados Unidos, las fuerzas capitalistas se han visto atrapadas entre, por una parte, la tendencia a ver en el aumento de la asistencia la posibilidad de retomar et control de la fábrica mediante la expulsión de una clase ya ingobernable y tratando de poner en práctica profundas reestructuraciones, $y$, por otra parte, la dificultad para financiar la asistencia misma en esta situación. El techazo de las condiciones de trabajo que efectivamente se daban reduce la cantidad de fuerza de trabajo entregada y al mismo tiempo aumenta la demanda de welfare y de calidad de vida, ampliando la lucha de fábrica a lucha social, a lucha urbana.

El «estilo de vida alternativo» que se crea en el interior de este complejo movimiento se caracteriza esencialmente por el rechazo del trabajo o, mejor aún, por el rechazo de la ética del trabajo, bien se trate de las instituciones de disciplina que en el Estado keynesiano habian visto incrementar incesantemente su extensión y su socialización (familia, es. cuela, reclutamiento de masas), bien se trate de las instituciones de la legitimación (contratación sindical y participación política), todas entran por igual en profunda crisis. En consecuencia, no sólo se trata de crisis de disciplina - la que, como se ha visto, ya se ha puesto profundamente en discusión a partir del taylorismo-, sino de crisis de consenso, de la disciplina contratada, de la «participación democrática». Una vez más, y también aquí, se sigue una evolución característica que pasa, a través de la "explosión» de las instituciones, de las exasperaciones de los procesos de «democratización» en los años sesenta, at surgimiento de una repentina y creciente desconfranza en ellos durante los setenta. Todos tecordamos 
la evolución de esta crisis, aunque en tiempos y revistiendo modalidades distintas (aunque no demasiado) en las distintas sociedades (capitalistas occidentales), las revueltas y luchas en las distiritas instituciones (escuelas, universidades, cuarteles, familias, cárceles, sirdicatos, etc.), el surgimiento de una lucha abierta (y luego de desconfianza tespecto a ellas) contra las formas de la democracia representativa, inclusive con episodios de lucha armada, bajo modalidades diversas en las disintas sociedades.

El discurso de Foucault sobre la indisciplina, sobre la microfísica del poder, surge, pues, tras años de indisciplina, de cuestionamiento de las relaciones microfísicas del poder. Por otro lado, probablemente el discurso de Foucault to sea más que uno de los más afortunados, en el área latina, entre los que tienden a poner en evidencia la construcción social de lo que definimos en nuestros discursos como raalidad o verdad, a «indisciplinat» las disciplinas científicas. Baste pensa: en la filosofía de la ciencia, de Wittgenstein a Kuhn, en el antirracionalismo y en el relativismo de Feyerabend, momento central del desarrollo cuyo problema -tal como él mismo lo cuenta $(1978,118)$ - fue el ce la relación entre la dominante tradición académica occidental y el ingreso en la por entonces agitada Berkeley (1964) de las minorías a las que se les había destruido la cultura, a saber: mexicanos, negros, indios, etc. $\mathrm{O}$ bien en los análogos desarrollos de la sociología, en la que la emetgencia de los lifestyles alternativos durante los primeros años sesenta influyó radicalmente la propia observación sociológica. No es casual que se haya dado tan fuerte impulso a este proceso de la sociología de la desviación. Dada la propia característica del objeto de la observación sociológica, la emergencia de un punto de vista "alternativo» sobre el objeto de análisis se sonvierte también de manera inmediata en un nuevo planteamiento epistemológico de las ciencias sociales (Pitch, T., 1977, 55 ss.). La identificasión del investigador con el mundo del underdog, con el mundo cool de los drogados, de los músicos de jazz, de las prostitutas, de la noche, desplaza el foco de atención del análisis - como lo observata Gouldner en un célebre artículo (1968)del objeto definido al poder de definición. Por último, el lenguaje reiterativo, obsesivo, itónico, mutilado, de la gran música urbana negra de la segunda postguerra, de Charlie Parker a Ccltrane y a Anthony Braxton, desorganiza y disgrega también la gramática del poder, obliga a reformular los discursos dominantes.

Al mismo tiempo, sin embargo, las operaciones de los años treinta y los nuevos equitibrios que éstos crearon, :ransformaron definitivamente la estructura político-económica, favoreciends una identificación cada vez mayor de poder político entre Estado y cúspide de las corporations, fuesen éstas o no (desde el punto de vista de la ptopiedad) de dominio público. 
Este proceso, junto con otro de creciente democratización, pone a las organizaciones políticas de clase cada vez más cerca de la posesión del aparato estatal, cada vez más cerca de la conclusión del período histórico que se iniciara con la organización y la constitución del movimiento obrero en partidos políticos. Por lo demás, la aproximación de estas fuerzas políticas al poder sí permite ver con claridad que, en el capitalismo moderno, el poder político dispone efectivamente de la posibilidad de dirigir ampliamente los procesos de acumulación, a la vez que constituye, en el marco de esta posibilidad, la verificación del límite que la esfera de lo político no parece estar en condiciones de trascender. En efecto, dirigir los procesos de acumulación no significa eliminarlos, no significa eliminar la realidad de la explotación, del trabajo asalariado, del antagonismo entre capital y trabajo. Más bien al contrario, precisamente el hecho de que las organizaciones obteras se aproximen al epílogo victorioso de una lucha contra la competencia de otras clases y capas sociales por la dirección del poder público, hace surgir la contradicción fundamental entre capital «social» y clase obrera de una manera aún más clara y patente. Aquí parece residir el Hic Rhodus, bic salta!, que no se quita ni invocando míticas Tierras del Amor Fraternal, ni las aún más míticas Aurorales Violencias Proletarias. No es solamente el problema de la burocracia el que se plantea, el problema puramente político de cómo comunicar la base con la cúspide de la clase, convertidos hoy en base y vértice del Estado. Se trata también de la contradicción que subsiste en el seno de la clase, en el seno de cada individuo, entre él mismo como trabajo y él mismo como detentador de una cuota de capital, entre su interés en gozar de la plusvalía producida y su interés en trabajar lo menos posible, en conceder la mínima piusvalía posible al capital social (una contradicción que tal vez puede asumir el aspecto de conflictos internos a la clase, entre diversos segmentos de la misma). A estas alturas se entiende por qué la clase, o parte de ella, nunca tiende a abandonar la «macrofísica», el Estado y el instrumento de la política (en sentido estricto, de Estado) obrera: el partido, para atacar directamente al nivel de la «microfísica» los ganglios de la acumulación y reproducción social, la ética del trabajo, to bumano. Y entonces también se comprende por qué la lucha sobre los lifestyles, sobre los «estilos de vida», llegó a ser tan dominante en la cultura de las jóvenes generaciones, primero en Norteamérica y luego en Europa, y suplantase a la lucha «política». Las relaciones personales, el modo de vestir, la música, todo ello contiene mucha más política, expresa opciones más «radicales», que una política que es mera gestión del capital social.

La respuesta que se ha dado hasta ahora, por parte de la derecha, es la siguiente: la década de los setenta aún no ha terminado. El gran capital 
tiende a tecuperar su libertad de iniciativa, a desvincularse del Estado. Como observé en un debate hace dos años, sa abre paso una hipótesis de solución liberal-autoritaria como respuesta a la crisis de la solución socialista-democrática (Melossi, D., 1977, 293). Lic orientación esencial de esta respuesta es el ataque a la clase obrera de la gran industria y a su organización, tanto sindical como política, fundamento y al mismo tiempo ruina del Estado keynesiano. Baste recotdar alguncis momentos de la compleja fenomenologia de este ataque. La consolidacion de las corporations multinacionales, que permite jugar simultáneamente en distintos tabletos y desligarse de los problemas de «legitimación» cie los estados nacionales; la colocación de ciertas tecnologías en países del tercer mundo donde se supone que habrá que tratar con una clase obrera más «dócil»; el crecimiento de la composición orgánica del capital gracias a la inversión en sectores en que el uso de trabajo vivo se reduce al minimo (petroquímica, nuclear, etcétera); la orientación de capitales hacia e! "sector competitivo» de la economía, donde el trabajo está menos sindicalizado y, por tanto, tiene un coste más bajo; al aumento del trabajo «negło», la descentralización productiva, etc., etc. Naturalmente, estos movinientos de tipo "económico" tienen consecuencias muy importantes de tipo «sociopolítico», puesto que su tendencia general dominante es el ataque a una cierta composición de clase. Su corolario estriba en la producción de desempleo, y en el problema del control de este desempleo. En cierto mods, había también una versión de derecha de la demanda que se había planteado en los años sesenta. En efecto, a la negación del trabajo se respondió con la asistencia, abierta o encubierta; a la demanda de una calidad de vida no dominada por la ética del trabajo se respondió, sobre todo en Estados Unidos, tratando de crear ghettos de «libertad» dominados en realidad por la heroína y por la gran criminalidad organizada y «rodeada» por una fuerza de policía cada vez más numerosa y abundantemente financiada. Se volvió a proponer la utopía bippie bajo la forma de infierno, de los marginados y los débiles, operación a cuya legitinación contribuyeron no poco los restos de una cierta ideología libertaria y antiobrera de la década de los sesenta. No es asombroso que uno de los lugares comunes del rock de los años setenta, el rock nacido de los ghettos blancos de Nueva York o de Londres, constituya un ataque al lifestyle de la década anterior, al que se acusa de haber suministrado el tejido ideológico de una nueva opresión soft, hecha de sexo, música, psicofármacos (legales o no), macrobiótica, manias de vida sana y falsa participación: j《beat up the next bippy I see» amenaza el grupo punk de los «Dead Boys»! (Dancis, B., 1978, 72). Se ha tratado de calibrar así, de una manera extremadamente casual y provisoria, el aumento de los gastos en asistencia y policía (Takagi, P., Platt, T., 1978; CRCJ, 
1975) con la necesidad de no perder tampoco el control de las capas medias y obreras que constituyen el alma de las entradas fiscales, lo cual es una contradicción que ha llevado al surgimiento, por ejemplo en Estados Unidos, de movimientos que luchan por una drástica reducción de las tasas fascales (taxpayers' revolt) en una perspectiva de política social de cuño claramente neoliberal. $Y$ esta misma perspectiva es la que subyace a las grandes «cautelas antiinflacionistas» de los países más fuertes de Occidente en estos últimos años, cautela que hace pensar en que se ha elegido la vía de

«una recomposición del bloque histórico según las relaciones de fuerza existentes antes del derrumbamiento de los sistemas de relaciones industriales occidentales que se iniciaba con el mayo francés, y de veto contra cualquier proyecto de verdadera reforma del Estado orientada a la cuestión política y/o social» (Tatantelli, E., 1978, 110).

Se tratatía, pues, de una vieja receta cuya aplicación más reciente es el Chile de Pinochet, laboratorio experimental de los Cbicago boys del neoliberal Milton Friedman: la destrucción del sindicato, la privatización de la economía, «el corte de las ramas secas», la atracción de capitales extranjeros, la garantía del control autoritario de las masas, forzadas a un régimen de salarios bajos y de desempleo. Es muy claro lo que significa esta libertad: libertad del desarrollo capitalista del Estado, del sindicato, del poder de la clase obrera. Ésta es una de las posibles salidas de la explosión del estado keynesiano de la década de los sesenta, de la búsqueda de libertad de las fuerzas sociales que en esa época surgieron de los equilibrios sociales y políticos que se habían creado entre la crisis de 1929 y la Segunda Guerra Mundial.

Entre los años sesenta y los setenta se hace añicos, en el campo de las instituciones de control social, la hipótesis de la extensión universal de la fábrica, ligada a la política intervencionista y de pleno empleo que se había lanzado en los años veinte y treinta. ¡No se entiende por qué habría que enseñar disciplina de fábrica y ética del trabajo a quien posee perspectivas prácticamente nulas de dejar alguna vez el ghetto de la asistencia! Con mayor razón aún en una situación en que los movimientos de los años sesenta dieron una clara lección: la de que las nuevas generaciones no quieren saber nada de esta disciplina, de esta ética, como lo demuestran las luchas en las escuelas y en las universidades, en las cárceles, en los ejércitos, en los hospitales psiquiátricos. Las que habrian de llegar a ser famosas como «instituciones totales》 (Goffman, E., 1968), inventadas siglos ha cotno una especie de monumento a la fábrica y a su poder, parecen 
hoy tremendamente obsoletas. Y por ello las propuestas de «apertura» de las instituciones, de integración «en el territorio», resultan cada vez más exitosas. Andrew Scull, con referencia al iaso de Estados Unidos y al de Inglaterra, observa que el proceso, sostenido por las fuerzas progresistas y de izquierda, que él define como excarcela:ión (1977), trimnfa cuando se encuentra con las necesidades de aumento de rigidez financiera que impone la crisis fiscal del Estado. Pero la crisis fiscal sólo es lo aparente del problema. En efecto, como ya he recordado y como se ha advertido a propósito del libro de Scull (Matthews, R., 1979), el gasto invertido en la institucionalización se corta en el momento en que crece el de la asistencia y la policía. Además, no se ha dicho que la «intervención en el territorio» sea menos costosa que la institucional. Deperde exclusivamente de cómo se realice. Todo este proceso, en consecuencia, sigue adelante porque el tema de la crisis fiscal lo utilizan las fuerzas de detecha, al menos en Estados Unidos (Scull, A., 1977, 134 ss.), para apoyar la clausura de ciertas instituciones (hospitales psiquiátricos y refornatorios antes que cárceles) según una estrategia general de control social oue, en la crisis, cumple ciertas opciones politicas. Podemos verificar a este respecto el modo de operar de la más general opción neoliberal.

Esta opción se encuadra en una elección de fondo que tiende a expeler de la producción a la clase obreta, a sustituirla por máquinas o por clase obrera «dócil» del Tercer Mundo y a controlarla de alguna manera mediante estrategias diferenciadas. Esta línes. hace suya la retórica del sesenta y ocho acerca de la «liberación», acerza de la «alteridad», la «alternatividad», la ideología tomántica $y$, a fin de cuentas, biologista sobre la existencia de una naturaleza de algún modo coartada por el «sistema» y crea un laboratorio en el que esta naturaleza pueda explayarse libremente: el ghetto. El ghetto es realmente la encrucijadiz en donde se encuentran el neoliberalismo de cierta nueva izquierda (la «a: stonomía», el «sujeto», etc.) y el neoliberalismo capitalista. Contra la fábrica, contra Ia socialdemoctacia, contra el gulag, la idcología de cierta nueva izquierda (no casualmente europea) conquista victoriosamente el ghetto: Il black out de Nueva York se convierte en su Comuna de París. Las instituciones «alternativas», desde las free clinics al pequefio artesanado, cada vez más precarias, y la gran industria de la droga y de las diversiones (ila disco!), cada vez más florecientes, aseguran la «calidad de vida» y sobre todo el control del ghetto. Criminalidad organizada y policía dominan alli de mutuo acuerdo (Chambliss, W. J., 1978).

Se tolera la criminalidad menor, pues ésla, contrariamente a las teorías románticas del delito al estilo de Robin lfood, golpea sólo a los más débiles, como lo demuestra el que la tasa de victimización de los negros 
norteamericanos sea seis veces mayor que la de los blancos y que el homicidio sea la «cuarta causa de muerte» entre los negros, «sólo superada por las enfermedades cardiocirculatorias, los tumores malignos y los accidentes» (Platt, T., 1978, 30). La policía rodea el recinto del ghetto y asegura que la infección no se propague a los suburbs de la clase media blanca.

A esta libre cloaca se arrojan los rechazos sociales «no institucionalizados», al merzos en las grandes metrópolis. El proceso se define como community treatment pero dado que el consenso acerca de ello se recogió en ciertos sectores sociales, principalmente sobre la base de la retórica de la crisis fiscal, el único tratamiento que se practicó fue el de los psicofármacos legales, los que, junto con los ilegales, forman parte de los instrumentos de pacificación del ghetto (Schrag, P., 1978). Completan el cuadro los tnedios de vigilancia electrónica y la difusión a pequeña escala de la psiquiatrización, también gracias al tejido "alternativo» (Castel F., Castel R., Lovell A., 1979), al menos en lo que respecta a la excarcelación de quienes eran recluidos bajo la etiqueta de enfermo mental. En cuanto a los excarcelados de las cárceles propiamente dichas, es menester recordar que más de la mitad de quienes son sometidos a algún tipo de restricción de la libertad personal, ni siquiera entran en la cárcel. En Estados Unidos, la probation constituye estadísticamente la sentencia condenatoria típica (Jankovic, I, 1977). En este país, el sesenta por ciento de los que se hallan bajo el control de la autoridad correccional está, precisamente, en régimen de probation (LEAA, 1976). La población catcelaria, por otra parte, no disminuye, pero se mantiene en un nivel más o menos proporcional a la extensión del desempleo (Jankovic, I, 1977). Estos «controles en libertad»s señalan, pues, una ampliación del control, en cuyo centro permanece firmemente el núcleo de la pena carcelaria, usada como garantía de control interna al sistema de control. A esto se le ha llamado el sistema de las cajas chinas (Cohen, S., 1975, 450) o la estrategia de tijeras del control social (Pavarini, M., 1978; Matthews, R., 1979).

Si tomamos una vez más a Estados Unidos como área significada de este proceso, hemos de considerar también la gran articulación de clase del sistema escolar, casi inexistente en el ghetto y que, en cambio, suministra servicios de altísimo nivel a las clases medias y altas, así como la desaparición del servicio militar obligatorio, para comprender cómo toda una estrategia de disciplina creada en el período del capitalismo clásico (jel viejo Panopticon!) y que se entendió universalmente en las primeras décadas de este siglo por la intervención estatal, ha sido casi definitivamente superada al mismo tiempo que aquel sistema de fábrica que constituía su modelo inspirador. En su lugar se desarrolla cada vez más un sistema de control que tiene en la asistencia, en el control de policía y en la 
industria de la «diversión» sus pilares básicos. Se trata de orientaciones típicamente «norteamericanas», pero cuyas huellas se advierten con creciente consistencia también en los otros países industriales, en particulat en los europeos. La concentración de las prácticas le control social en el ghetto y la ampliación de éste en conexión con las tendencias fundamentales del desarrollo capitalista tras el welfare, hacen que la cuestión del control social y de la desviación coincida cada vez más con una cuestión política más general: la abierta crisis política del molelo socialista-democrático y la explosión de una reacción de dereça de cuño neoliberal -reacción de la que forma parte esta nueva política penal, ya sea definida como neorrealista (Tagaki, P., Platt, T., 1978) ya como reoclásica o neoconservadora (Hoffman, D., Blake, G., 1978) m es un hicho que plantea cuestiones absolutamente radicales. Ante todo, pone a las fuerzas de izquierda ante la drástica opción entre, por un lado, un proyecto de gestión del capital social respecto al culal no se advierte cómo habrá dè evitarse la ulterior profundización de la indisciplina y la formación de shettos, y, por otro lado, el hacerse cargo de una investigaciór difícil y tormentosa que intente someter los movimientos del capital a la autonomía de clase, a las necesidades de clase. No se trata de teplantear proyectos detrotados, como el de las masas «dentro del Estado", sino de respetar, de "garantizar» la autonomía de clase incluso a través de la acción de gob:erno, incluso sirviéndose de un instrumento tan poderoso como el estatil. Si este garantizar puede tener sentido hoy sin ser mera tautología, este hecho puede significar el reconocimiento (y la garantía) de la autonomía de las opciones de vida, culturales, organizativas, etc, de quien rechaza esta organización del trabajo, esta moral, esta política. Pero para que este rechazo no se vuelva absolutamente devastador, la izquietda ha de estar en condiciones de autonomia adecuadas como para traducir en política estas necesidades, no para asumirlas o integrarlas en la política, sino a fin de que sea posible actuar, desde el Estado, para garantizarias. Para que, a través del poder del Estado, sea posible comenzar a experimentar al dominio del trabajo vivo sobre el trabajo muerto. Para que la liberación! del trabajo no sea sinónimo de creación de ghettos.

\section{Dario Melossi}

Facultad de Jurisprudencia

Universidad de Bolonia

Bolonia (Italia) 


\section{Bibliografia citada en el texto}

Annette, J. (1979), Bentbon's Fear of Hobglobins; Law, Political Economy, and ocial Discipline, en NDC/CSE, encatgado de edición, «Capitalism and the Rule of Law», Londres.

Bentham, J. (1962), Panopticon, en «The Works», IV, Nueva York.

Blumstein, A., Cohen, J. (1973), A Tbeory of the Stability of Punisbment, «The Journal of Criminal Law and Criminology», 64, 2 (junio).

Bologna, S. (1972), Composizione di classe e teoria del partito alle origini del movimento consiliare, en «Operai e stato», Milán.

Braverman, H. (1978), Lavoro e capitale monopolistico, Turin.

Cacciari, M. (1972), Sul problema dell'organizzazione. Germania 1917-1921, Introduc. ción a G. Lukàcs, Kontmunismus 1920-1921, Padua.

Cacciari, M. (1978), Alcune riflessioni sul «nuovo modello», en A. Duso, Keynes in Italia, Bari, pp. 149 ss.

Calvi, G. (1979), Lo spazio del padrone e il tempo dell'operaio: alcune ipotesi di lavoro sull'America del primo novecento, comunicación presentada en el seminario organizado por el ISSOCO, sobre «Cultura operaia e disciplina industriale», Roma, 17-20 abril 1979.

Castel, F., Castel, R., Lovell, A. (1979), La société psycbiatrique avancée, París.

Center for Research on Criminal Justice (CRCJ), (1975), Tbe Iron Fist and the Velvet Glove, an analysis of the U.S. police, Berkcley.

Chambliss, W. I. (1978), On the Take. From Petty Crooks to Presidents, Bloomingten.

Christie, N. (1968), Changes in Penal Values, «Scandinavian Studies in Crimino+ $\log y), 2$. 
Cohen, S. (1975), Uno scenario per il sistema carceario futuro, en F. Basaglia y F. Basaglia Ongaro, «Ctimini di pace», Turín, p. 441.

Dancis, B. (1978), Safety Pins and Class Struggle: Punk Rock and the Left, «Socialist Review», 39 (mayo-junio), p. 58.

De Grazia, V. (1978), La taylorizazione del tempo libero operaio nel regime fascista, «Studi storici», abrit-junio, 2, p. 331.

Deleuze, G. (1976), Non uno scrittore: un nuovo cartografo, en «Deleuze», Cosenza, p. 29.

Dobb, M. (1972), Problemi di storia del capitalismo, Roma.

Donzelot, J. (1978), Miseria della cultura politica, «Aut-Aut», 167-168, p. 115.

Evans, R. (1970), Panopticon, «Controspazion, II (1970), 10, p. 4.

Feyerabend, P. (1978), Science in a Free Society, Londxes.

Foucault, M. (1976), Sorvegliare e punire. Nascita della prigione, Turín.

Foucault, M. (1977), Microfisico del potere, Turin.

Freud, S. (1971), Psicologia delle masse e onalisi dell'Yo (1921) en \&Il disagio delia civiltà e altri saggi», Turín.

Freud, S. (1977), Analisi terminabile e interminabile. 19:17, en "Analisi terminabile e interminabile. Costruzioni rell'analisi», Turín.

Goffman, E. (1968), Asylums, Turín.

Gouldner, A. W. (1968), The Sociologist as Partisan: Sociology and the Welfare State, «The American Sociologist», 3, mayo, p. 103.

Gramsci, A. (1975), Quaderni del carcere, Turín.

Greenberg, D. (1977), The Dynamics of Oscillatory Punibment Processes, «The Journal of Criminal Law and Criminology», 68, 4.

Himmelfarb, G. (1968), The Hounted House of Jeremy Bentham, en «Victorian Minds", Nueva York.

Hoffman, D., Blake, G. (1978), Neo-conservative Criminology: Roots and Futures, comunicación presentada en la conferencia anual de la «Western Society of Criminology", San Diego, California.

Hotkheimer, M. (1949), Autboritarianism and the Family Today, en Anshen, encargado de edición, «The Family: its Function and Destiny", Nueva York.

Horkheimer, M. y otros (1974), Studi sull'autorità e la tamiglia, Turín.

Huxley, A. (1949), Prisons, introducción a Carceri metafiticbe de G. Piranesi, Londres. Ignatieff, M. (1978), A Yust Measure of Pain. The Penitentiary in the Industrial Revolution 1750-1850, Londres.

Jacobs, J. B. (1977), Stateville. The Penitentiory in Mas, Society, Chicago.

Jankovic, I. (1977), Labor Market and Imprisonment, «Crime and Social Justice», 8, otoño-invierno.

Jervis, G. (1975), Manuale critico di psicbiatric, Milán.

Kinsey, R. (1978), Marxism and the Law: Preliminary Analyses, «British Journal of Law and Societys, 2, p. 202.

Lea, J. (1979), Disciplina e sviluppo capitalistico, «La questione criminale».

LEAA (1976), Report to the Congress by the Comptroller General of the U.S., State and County Probation: Systems in Crisis, Dejt. of Justice, 27 mayo.

Markus, T. (1954), Pattern of Law, \&The Axchitectural Review», 116, 694, octubre.

Marx, K. (1950), Critica della filosofic del diritto di Hegel. Introduzione, en «Scritti politici giovanilì, Turín.

Marx, K. (1970), Il capitale, Roma.

Matthews, R. (1979), Andrew Scull's Decarceration: A Critical Review, in NDC/CSE, encargado de edición, «Capitalism and the Rule of Law», Londres. 
«Papers»: Revista de Sociologia

Melossi, D. (1976a), Istituzioni di controllo sociale e organizzazione capitalistica del lavoro: alcune ipotesi di ricerca, "La questione criminale», II, 2/3 (mayo-diciem. bre), p. 293.

Melossi, D. (1976b), Statistiche «della criminalità» e carcerarie in Italia, «Inchiesta", VI, 21.

Melossi, D. (1977), Intervento nel dibattito: Ordine $e$ democrazia nella crisi: un dibattito interno alla sinistra, «La questione criminale», III, 2 (mayo-agosto), p. 286.

Melossi, D. (1978), Mercato del lavoro, disciplina, controllo sociale: una discussione del testo di Ruscbe e Kircbbeimer, introducción a Rusche, G., Kirchheimer, O. (1978).

Melossi, D. (1979), Carcere, fabbrica e storia: alcune osservazioni sulla letteratura più recente, «La questione criminale».

Melossi, D., Pavarini, B. (1977), Carcere e fabbrica, Bolonia.

Mill, J. (1824), Prisons and Prison Discipline, «Encyclopaedia Britannica», suplemento a la cuarta ed., VI, Edimburgo.

Mitscherlich, A. (1969), Verso una società senza padre. Idee per una psicologia sociale, Mitán.

Nietzsche, F. (1977), Genealogia della morale, Roma.

O'Connor, J. (1977), La crisi fiscale dello stato, Turín.

Offe, C. (1977), Lo stato nel capitalismo maturo, Milán.

Pasquino, P. (1978), Theatrum politicum. La genealogia del capitale - la «polizia» e lo stato di prosperità, «Aut-Aut», 167-168, p. 47.

Pasukanis, E. B. (1975), La teoria generale del diritto e il marxismo, Bari.

Pavarini, M. (1978), «Concentrazione» $e$ «diffusione» del penitenziario. La tesi di Rusche e Kircbheimer e la nuova strategia del controllo sociale in Italia, apéndice a Rusche, G., Kirchheimer, O. (1978).

Pitch, T. (1977), Sociologia alternativa e Nuova Sinistra negli Stati Uniti d'America, Florencia.

Piven, F., Cloward, R. (1972), Regulating the Poor. The Functions of Public Welfare, Londres.

Platt, T. (1978), «Street» Crime - A View from the Left, «Crime and Social Justice», 9 (primavera-verano).

Polanyi, K. (1974), La grande trasformazione, Turín.

Procacci, G. (1978), L'economia sociale e il governo della miseria, «Aut-Aut», 167-168, p. 63.

Rajchman, J. (1978), Nietzscbe, Foucault and the Anarcbism of Power, «Semiotext(e)», 1, p. 96.

Rella, F. (1978), Il mito dell'altro. Lacan, Deleuze, Foucault, Miłán.

Rusche, G., Kirchheimer, O. (1978), Pena e struttura sociale, Bolonia.

Schrag, P. (1978), Mind Control, Nueva York.

Scull, A. (1977), Decarceration, Community Treatment and the Deviant: A Redical View, Englewood Cliffs (N. J).

Sellin, T. (1944), Pioneering in Penology, Filadelfia.

Snare, A. (1977), Work, War, Prison and Welfare: Control of the Laboring Poor in Sweden, disertación de doctorado en criminología, Universidad de California, Berkeley.

Takagi, P., Platt, T. (1978), Intellettuali per la legge e l'ordine: una critica dei nuovi «realisti», «La questione criminale», IV, 2 (mayo-agosto), p. 217.

Tarantelii, E. (1978), Il ruolo economico del sindicato e il caso italiano, Bari. 